\title{
Energy global governance in a philosophical perspective
} Barbara Przybylska-Czajkowska ${ }^{1}$, Waldemar Czajkowski ${ }^{2}$

1 Silesian University of Technology, Gliwice, Poland; bprzybylska@polsl.pl
2 Silesian University of Technology, Gliwice, Poland; wczajkowski@polsl.pl*
* Correspondence: wczajkowski@polsl.pl

Abstract: In the present paper some questions related with energy global governance are discussed. These questions are viewed as a part of the broader problematics of globalization. Due to the very complex nature of this problematics the role of philosophy - in particular analytical and science-based philosophy - is emphasized. We underscore the importance of philosophy for the developing global consciousness and - indirectly - for the development of global society.

Keywords: 1 . globalization; 2. Spaceship Earth; 3. regulation

\section{Introduction}

There is no doubt that humanity (or - if you accept this, rather controversial, term lobal society) faces a great many challenges. Some of them are very serious: so serious hat, at least in the view of certain scientists and thinkers, the very existence of humanity at stake [1].The challenges posed by ecological and military problems (in other words: issues of security) are surely among the most serious. And many of these problems are various and complex ways - determined by the processes of production and distribution of energy. The conclusion of this reasoning is simple and obvious: the possibly high quality of energy global governance belongs to the main goals to be pursued (and achieved) by the global society.

The possibility of achieving such a goal by the trial-and-error method cannot be excluded. But the probability of the success of this strategy seems to be (rather?, very?) low. In turn, as historical experience strongly confirms, strategies based on relevant knowledge are much more promising.

Knowledge (most likely on whatever subject) we have today is surely much greater than that we had still a few decades ago. However, this claim demands two reservations. First, our knowledge is not complete, precise etc. Also, we often lack instruments to evaluate epistemologically our (supposed) knowledge. And second; our knowledge, however incomplete, is too large to be mastered by politicians, social activists, journalists and interested citizens.

We are convinced that constructing syntheses of our knowledge is an important task to be realized by academicians by philosophers in particular: Philosophy, since its origins in ancient Greece, has always been oriented mainly at the World (Universe, Being...) as a whole, and at its particular domains - in the context of the World. We think that this orientation - characteristic for philosophy - is today, in the $21^{\text {st }}$ century, much more important than it has been for ages: Philosophy has been satisfying various (sometimes fundamental, sometimes rather sophisticated) intellectual/spiritual needs; we do hope that our discipline will also play this role in the future. But we also hope that it will play a different role - the role of an important instrument to deal with global challenges.

Having presented, in a very brief form, the main ideas of our text, we would like to supplement our opinion that philosophy has in our age an important role to play. This opinion is a consequence of two others. The first one concerns the process of globalization, the second - knowledge and its development. 
We are thus beginning from some remarks on globalization. Various definitions of this term have been proposed [2,3]. We are not going either to choose one of them or to offer our own. We think that the variety of the definitions reflects two aspects of the changes undergoing in the world during the last decades. (The nature of these changes, their mechanisms, roots and possible consequences can be interpreted variously; that the world is in many ways deeply different than, say, two or three decades ago - it is beyond any serious debate') Firstly, the variety and complexity of these changes [4,5]. Secondly, the fact that these changes are experienced and evaluated in greatly variegated ways.

We want to indicate three processes which, in our opinion, are important elements of the changes grouped under the umbrella of "globalization". The first, most obvious, is the increasing interdependence of societies (states, continents etc.) The second (a consequence of the former and of the development of technology), is the increasing complexity of the world. And the third, the rise of global problems (to a considerable degree - an effect of the economic and technological developments) and challenges.

We tend to think that these processes also result in the fourth one: the rise of global society: There are some common objective interests of all humans. And there are some elements of the awareness of these interests - some elements of global social consciousness [1]. (We do agree: this process is very slow and faces many very serious obstacles). So much about globalization,

Now, let us make some comments on the current development of knowledge and on some its relations with the process of globalization. Characterizing very briefly this development, we might underline three its aspects. Firstly, the growing amount of empirical information. Secondly, the increasing number of scientific theories, methodologies, paradigms...Thirdly, the growth of intellectual production - of books, journals etc. This growth has undoubtedly many positive consequences. But, some researchers believe (and we tend to accept this opinion) that some consequences of this growth are negative. To put it in other words: the development of knowledge helps us - to greater and greater degree - to manipulate various, relatively small, parts of the world. But, at the same time, our understanding of the world (this part of the World in which we live and which is of practical, direct importance for us). Finding some solutions to this problem is one of the global challenges humanity (and, in particular, scientist) should respond to .

\section{Materials and Methods}

Let us start with a few remarks on the methods we have applied in the present study. These methods have determined the types of materials we will use here.

As already declared in the title of our paper, it is of a philosophical nature. As it is well known, philosophy is a very differentiated domain of culture: various philosophies (philosophical systems/orientation) present very different images of the world (philosophical theories) and avail of varied methods of their construction and justification. For this reason we consider it necessary to present (though in a very succinct form) the approach to philosophy we accept and assume in the present text. Two concepts could be used as a label for this approach: analytical philosophy and scientific philosophy. A few short comments about each of them should be formulated.

Firstly, about analytical philosophy [6]. Leaving aside the problem of its historical roots (as almost everything in philosophy, they could be looked for in the ancient Greece), analytical philosophy has been the most important trend in the philosophy of the $20^{\text {th }}$ and $21^{\text {st }}$ centuries. It is also very differentiated. However, regardless of all those "internal" differences, some its basic traits (common to all its sub-trends) can be rather easily defined. First: the importance attached to the precision of language used in philosophy; it could be said that - from the analytical point of view - the language of philosophy should be as similar as possible to that of mathematics. And second: also the philosophical argumentation should be possibly close to that of mathematics or of empirical/exact sciences. 
Secondly, a remark on scientific philosophy. This term is very often used in such a way that it could be regarded as almost synonymous with the notion of analytical philosophy. However, in the context of the present text, we would like to characterize the meaning of the term "scientific philosophy" in a more specific way. Briefly put, we want to regard as "scientific" such a philosophy which is based on (natural and social) sciences. In other words: scientific philosophy constructs images of the world using elements (concepts, data, etc.) provided by various scientific disciplines. Formulating it in a still different way, it could be said that scientific philosophy synthesizes the images of some parts of the world (delivered by particular scientific disciplines) into comprehensive ones.

To this very brief characteristic of scientific philosophy, we would like to add a remark on its philosophical character. Putting it otherwise: we would like to say why, in our opinion, this synthesizing activity is to be treated as philosophical. A short answer can be formulated in two points. First. Epistemological evaluation of our knowledge of the world should be a part of any of its (sufficiently comprehensive) images. A systematic overview of this problem cannot be offered here. But at one its aspect is to be men tioned. We mean the knowledge of non-knowledge, otherwise put: about lacunae in our knowledge, and about their consequences for humans. And just here we arrive at the second point: Philosophical synthesis contains also opinions (hypotheses) about consequences for humanity of the state of world (on the assumption of the validity of the image presented by the given synthesis).

Now, we would like to say some words on the relations between philosophy and ideology. (Let us make here at list a "link" to history of philosophy: this issue is connected with formulated by David Hume thesis about logical/methodological distinction between theorems on facts, or on "what is", and theorems on values, or on "what should be" [7].) This problem seems to be of particular importance in the context of the main subject of this text. This importance results from two facts. Firstly, the ecological problems (very closely, as it is well known, connected with those of energy) are problems which gave rise to the development of various "green" (ecological, environmentalist) movements and - their ideologies (environmentalism or rather - environmentalisms of various kinds). Secondly, philosophy - on the one hand - indicates that in our pre-theoretical (pre-scientific) every-day thinking very different elements (perceptions, expectations, fears, moods etc.) are strongly interconnected; on the other hand, philosophy tries to "deconstruct" this pre-theoretical thinking. Let us say that, in our opinion, this "deconstructing" (or critical, also - self-critical) activity is an important task of philosophy.

So much about methods. And now some comments about materials. It obvious that philosophers (qua philosophers; this remark seems to be important since, on one hand, some scientists, e.g. physicist L. Lederman or biologist E. Wilson, can be regarded as philosophers, and on the other, some professional philosophers, e.g. D. Dennett, participate in scientific researches) do not conduct any empirical researches. If they accept, as we do, the program of scientific philosophy, they regard scientific texts as the materials of their own analytical/theoretical work. Obviously, this is also the strategy adopted in this article.

Virtually all strategies of intellectual (in particular: scientific and philosophical) activities generate some specific troubles. How we could characterize the troubles resulting from the strategy described in the previous passage? Most briefly put, it can be said that the immense number of the relevant texts is the source of the troubles we have faced while preparing this paper. We are not sure that we have fully managed to overcome these troubles: we were not able even to bring on our desks a considerable number of those texts, not to mention about their analysis. We have consulted a limited number of texts satisfying simultaneously the condition of importance and that of accessibility. We have also tried to avail of texts representing various research areas and various theoreti$\mathrm{cal} /$ methodological orientations. Thus, one could say that the area of our interest has been merely initially explored. But, on the other hand, we are inclined to guess that this limi- 
tation has a positive aspect: Even the analysis of the relatively small number of texts allowed us to sketch an outline of the problematics we are interested in.

We are going to continue our investigations of this problematics. We suppose that this text will support our future decisions about texts to be read (due to the number of texts such decisions are today necessary in in all fields, perhaps except very narrowly defined domains). We think that it should help us in reading the selected texts - in formulating such questions as: "In which way our image of the problematics should be modified, in which - concretized, and in which - supplemented?"

Having formulated the above explanations, let us go to the presentation of the literature we used while preparing this article. We will focus our attention only on the main important texts, or even - groups of texts.

We would like to begin from the reports to the Club of Rome. For the last fifty more than forty reports have been published; there is no place here to just enlist them all. (One could also add that some of them are devoted to relatively narrow problematics, rather distant from the key issues of our paper.) Five of them deserve - in the context of the problematics discussed here - particular attention. Obviously, one has to start from "Limits to Growth" - just this text introduced many important ideas that have been discussed to this day: the idea of global system, of exponential growth and of - the exposed in the title - limits to growth [8]. One should also not forget that this report avails of the method of computer modelling; probably for the first time. In our view, just the introduction of these concepts and methods - and not specific predictions - decide on the lasting historical importance of this text. The second report to be mentioned her is titled "Beyond the Limits. Global Collapse or Sustainable Future" [9]. It was prepared on the occasion of the twentieth anniversary of the publication of the "Limits..." and confronts the global situation in the 1990s with the prognoses the "Limits..." contain. After next twenty years another report - "A Global Forecast for the Next Forty Years: 2052" was published [10]. If to compare - in a very concise way - this report with the first one, one could note the greater emphasis put on alternative (possible nut not necessary) "futures", the "nonmaterial" (cultural etc.) issues are debated and areas (Europe, BRISE etc.) specificities are analyzed. Still two reports are to be mentioned: "The First Global Revolution" and "Come On! Capitalism, Short-termism, Population and the Destruction of the Planet" $^{\prime \prime}[10,11]$. Both contain some elements of analysis of the current and future situation of mankind, but (as their titles suggest) are, so to say, solutions-oriented: they present concrete proposals how we should response to the global challenges.

Since the idea of "limits to growth" is important, and perhaps the most widely known of all developed by the Club of Rome, we want to mention at least two books important its discussion. We mean here "The No-Growth Society", a collection of texts issued a few decades ago by M. Olson and H. Landsberg, and "Green Growth, Smart Growth..." (note the telling title) published a few years ago by R. Fuchs [12,13].

As regards the general concept of globalization, we used "Globalzation: A Critical Introduction" - a very comprehensive, systematic, and (what is of particular importance in the case of so hotly debated issue) non-partizan book, authored by A. Scholte [2]. Our concept of globalization draws also upon theories of complexity. A very systematic, mathematics -based analysis of this concept is contained in the K. Mainzner's work "Thinking In Complexity: A Computational Dynamics of Matter, Mind, and Mankind".[4] Less formal but very inspiring (first of all we mean here the idea of mankind as one collective adaptive system) is "Quark and Jaguar..." - the book of the great physicist M. Gell-Mann [5]. In establishing connections between theory of globalization and theory of evolution (Spencerian perspective) particularly useful turned out to be the work of a prominent biologist J. Maynard Smith (co-authored by E. Szathmary) "The Origin of Life. From the Birth of Life to the Origin of Language".[14]

An important role have played in our studies the texts devoted to axiological (ethical) aspects of globalization, global challenges and responding to them. Among them of special importance is still - in our opinion - the work of H. Jonas. "The Imperative of Responsibility" [14]. B. Birnbacher's "Veantwortung fur zukinftige Genertionen" and P. 
Singer's "One World. The Ethics of Globalization" supplement in significant ways Jonas' work $[15,16]$.

The interpretation of the concept of power (with which that of governance is closely connected) proposed by M. Mann in his four-volume work "The Sources of Power" has been very useful for us [17]. Considering the problems of global governance we also used some crucial ideas (concerning the development of inter-human cooperation) outlined in R. Wards "Nonzero. The Logic of Human Destiny" [18].

We would like now to say something about philosophy of technology, or - to be more specific - about technology assessment. A. Grunwald's text presents tis interdisciplinary domain located at the border of philosophy and engineering sciences [19].

As regards energy, we have consulted a papers contained in the "Handbook of Energy Politics" [20].

\section{Results}

Today, after great many discussions held by historians and philosophers, it is rather obvious that for no epoch (either of history tout court or of history of a domain, say of football or mathematical logic or whatever) can be determined its undisputable "birth date". On the other hand, some dates can be regarded - and conveniently used - as indicating, to put it metaphorically, a moment in which a historical process entered its "maturity phase". As regards the process we are interested at this place, the year 1972 can be accepted as playing such a role: Firstly, the Stockholm Conference On the Human Environment (June 5-16); secondly, the publication of the first report to the Club of Rome. However we would like to evaluate the successes and fails of activities oriented at protection of our natural environment (strongly connected with the energy problems), one thing is beyond discussion: the last five decades have witnessed development of global (in particular: ecological) social consciousness which in turn resulted in many - more or less successful - practical actions. For these reason our further considerations will be devoted, almost exclusively, to the problems discussed since 1972. However, some steps back can be useful.

Let us make one - to 1966. In that year Kenneth E. Boulding, a prominent American economist and philosopher, published the essay titled "The Economics of the Coming Spaceship Earth"[21]. This text has played a significant role in the development of environmentalist thought and movements. Analysis of this role should be undertaken in another place; here we would like to make but a few brief comments on the metaphor contained in the title of the Boulding's paper. First: the phrase "spaceship Earth" suggests that our planet is obviously a natural (geological and biological) system but - simultaneously - a technical one; thus, the Earth is (or, to be more precise, is becoming) a complex natural-technical (and if technical then also - social) system. Second: as any system (and particularly: of the type suggested by the word "spaceship" denoting a means of transportation), it is composed of matter, information and - energy. Third: the concept of "spaceship" suggests that this system can and should be controlled (regulated).

We are going now to develop these remarks - in that order in which they have been formulated. Nevertheless, we would like to start from a very short comment on the last remark: It is rather obvious, but nevertheless - due to the importance of this fact and due to some its less obvious and also very important consequences - it should be stressed that effective control/regulation of any system (be it a human organism, a plane, a corporation or any other) presupposes knowledge about its structure and dynamics. Thus, if the "spaceship Earth" is to be controlled, the knowledge about this natural-technical-social system is badly needed.

Do we have such knowledge? Do we understand (in the sufficiently profound way) the "system-ness" of Spaceship Earth? Any simple answer (either positive or negative) should be, in our opinion, rejected: On the one hand, today almost for sure, we understand this system much better than, say, a century ago. 
The idea of Anthropocene sheds some light on the impact social and technical sub-systems exert on the natural one. Also our understanding of the natural sub-system seems to be more profound. On the one side - the ideas of James Lovelock (the Gaia hypothesis) and of Lynn Margulis (symbiotic planet), on the other - Peter Ward's Medea hypothesis (Earth as self-destructive system) though controversial, seem to be helpful in developing knowledge about one global natural system [22-24]. On the other hand, we understand still rather poorly the structure and dynamics of the third (i.e. social) sub-system. The causes of this fact would deserve a separate analysis. Here, we will formulate but three very short remarks concerning this question. First, on so-called postmodernism. It was a philosophical trend that had its roots back in the pre-war times but flourished and gained popularity in the 1970s and 1980s. Quite a few various ideas were grouped under this heading. In the context of the present text, one of them deserves particular attention: criticism and rejection of so-called "grand narratives"; all theories of global social process (of global History) were included among them and - rejected. Second, however strong was in those years the position of postmodernism, other orientations were also developing. We mean here first of all the ideas exposed in the four-volume work of Immanuel Wallerstein "Modern World-System" [25]. (Interestingly enough, its first volume was published in 1974 - only two years after "Limits to Growth"). It presents an interesting image of the development of capitalist system (presented as a global system, global - from its beginning in the $15^{\text {th }}$ century and by its very nature). This work also contains some more general ideas that, in our opinion, should be included into a general theory of global social process. Unfortunately, in its current form, it is a description of the past much more than theory delivering a basis for predicting the future. Third, quite recently the situation seems to be, from our point of view at least, improving: large number of important works about global history have been published during the last two or so decades. To a systematic overview of this literature a separate and rather long paper should be devoted. We will mention here only few titles, somewhat (but not quite) randomly selected. Perhaps we should start with David Christian's "Big History: From the Bing Bang to the Present" [26]. For a few reasons. First: the phrase "big history" has become quite popular and is regarded as the name of a scientific (sub-)discipline. And second: it has contributed to the revival of the Spencerian (and by many thinkers regarded as definitely outdated) perspective integrating natural and social/cultural evolution We would also like to invoke Leonid Grinin's and Andrey Korotayev's "Great Divergence and Great Convergence" in which the current process of globalization is studied in the context of very long history [27]. And still one example: J. R. McNeill's "Something New Under the Sun. An Environmental History of the Twentieth Century World" [28]. It is a descriptive study rather than a theoretical one but, on the other hand, closely linking natural sciences (hydrology, climatology, ecology etc.) with history and delivering large and well organized empirical basis for more theoretical studies. We should also note that it contains a chapter on "Energy history since 10.000 B.C."

This part of our considerations we would like to end with a few sentences on a sociological conception proposed by the French scholar Bruno Latour. We mean here so-called Actor-Network-Theory (presented in most systematic way in This theory, though "local" rather than "global", is one of the first to present human/social-material systems.

And what about the second (technical) sub-system? We tend to think that our knowledge of this sub-system is still today much poorer than that of natural sub-system (theory of biological evolution is a well-developed scientific discipline) and even that of social-subsystem (at least a number of interesting ideas have been proposed). Perhaps the "intermediary" nature of technical sub-system might, at least partly, account for this fact: Specialists in engineering sciences, disciplines included to the (wide and differentiated) domain of applied sciences, have been interested in developing new technologies (technical objects etc.) and not in studying the already existing (not to speak of those outdated). On the other hand, social scientists and humanities scholars have most often 
lacked specialist knowledge necessary for "internal" studies of technical systems - studies very different from the "external" ones (devoted to the interactions between technical and social or natural systems). Fortunately, the situation seems to improve recently: On the one hand we should mention the rise of a new discipline: "Earth systems engineering and management", on the other - the new developments in the philosophy of technology which result in relations with engineering sciences much closer than previously.

Now, we would like to formulate our opinion concerning dynamic features of this natural-technical-social system. Very succinctly put: Herbert Spencer was right: the Universe, our planet, the life on earth, the human society - all these systems have been evolving. Of course, analyzing Spencer's philosophy of evolution in detail, we would have to introduce various corrections and additions. But such an analysis is not here our goal. Referring to Spencer, we want to stress but two points. Primo, social evolution is a continuation of the biological one, and the latter - continuation of the cosmological. - It is a rather obvious fact (though some social sciences scholars representing so-called "anti-naturalist" ontology and methodology tend to reject it). Secundo: some analogies between various types of evolution seem also to be obvious. If so, an abstract theory of evolution (mathematical, basing on general system theory) is possible. And, we suppose, such abstract theory would be helpful with developing theory of the evolution of the global natural-technical-social system ("Spaceship Earth")

We suppose that such a theory is not only possible but also desirable if not - necessary. Formulating this opinion we ae are starting presentation of the elaborated form of our third remark on Boulding's concept of the "spaceship Earth" [21]. In its brief form it says, let us recall, that the concept of "spaceship" suggests that this system can and should be controlled (regulated). To put it in a (slightly or rather seriously?) modified form: the evolution of this system can and should be controlled

Some thinkers would definitely reject this opinion. The would say that it is a form of the outdated "Promethean myth", a manifestation of human conceit...We are not inclined to engage in such a discussion. But we do agree that we are partly responsible for suggesting it: Our opinion has been formulated too concisely; it needs additions, clarifications and reservations.

There is no slightest doubt that humanity has for millennia exerted some influence on the world of which it has been a part. But there is also no doubt that only recently (viewing in the global history perspective): for the last two or three centuries, this influence has been rapidly increasing and the pace of this increase has been also increasing. tIt can be expected that even if the level of the influence stabilizes in more or less distant future, it will remain very great anyway.

Thus, asking about controlling (regulating) evolution of our global (natural-technical-social) system, we ask in fact about controlling our own activity.

This issue can be subdivided into two sub-problems. The first one concerns the aims of this control: What goals are to be achieved by the development of the technical sub-system (the more technology is developed, the less evident are, in our view, the goals to be achieved by its further development), and what undesirable side-effects should be ecluded or at least limited.

The second question concerns the methods and - very important - the costs of controlling (regulating) our technological activities. Let us emphasize at once that the word "costs" - as used here - should be understood very broadly: it is to denote all undesirable consequences of control. Without debating in a long way this (both interesting and difficult) problem (a problem that is a part of one of the central problems of political philosophy/theory), we want to say what follows: In some cases (say: eating food) it is absolutely evident that the best (optimal) level of a system parameter (say: the quantity of calories) is neither this one which is maximal nor that one which is minimal (an observation of the sort of that formulated for the first time by Aristotle). In some other cases to discuss rationally the problem of optimality ideological attitudes have to be rejected (what often happens to be difficult, even - very difficult). For instance one has to reject both the ideology of totally planned command economy and that of unconstrained laissez 
fair economy to be able to ask the question about optimal level of (state or other) regulations. Referring to this - rather simple - argumentation, one should regard as evident that very complex and difficult is the problem of the optimal level of regulation of the development of technology and of the human influence on the natural sub-system.

To the considerations presented in the last three passages a comment has to be added - on criteria of regulation. Even in the case of many technical objects is not obvious what criteria are to applied while they are designed (e.g. what role is to be played by the durability of the given object). Also in medicine many axiological dilemmas, often of profoundly moral nature, arise (for instance: Is the length of individual's life more important that the individual's quality of life?). Therefore, one should not be surprised that in the case of such a complex system as "Spaceship Earth" the problem of the criteria of its regulation is extremely complex and - generating profound controversies. - This comment we would like to supplement with a brief note on the role of philosophy: Ethics (or, more generally, axiology ), a very important branch of it, has the leading role to play when the problems of the criteria of regulation are to be analyzed.

At this moment you might suppose that we would like to revive the old Plato's idea of the philosopher-king. Such a supposition, even if not incidental, is not correct - is not in accordance with our intentions. Of course, individual philosophers can also play some social roles other than that of philosopher. But however the "global controller/regulator" should be constructed (of whom should be composed), philosophers neither could nor should be a large part of this "controller" (without going into further details - to be discussed below - one point can already be made here: it is evident that a group of people and not a single person should play the role of "controller"). In our view, the role of philosophy and philosophers is on the one side important but on the other - only supportive: The task of philosophers (particularly in the case of axiological issues) is to precise the dilemmas to be solved, to indicate presuppositions and consequences of this or that solution of the given dilemmas - in other words: to support intellectually the decision-makers and not to impose this or that solution.

Having formulated some general comments on the problem of control/regulation of material activity of humanity, let us discuss some more specific (and very controversial) issues. We are going to commence from the problem formulated in (and popularized by) the "Limits to Growth" - the first report to the Club of Rome. One of the central ideas of this report could be summarized as follows: Our planet is (one might add: as any individual object in the Universe) a finite object; therefore unlimited use of mater and energy, thus no infinite growth (of material production), is possible. So limits to growth do exist. Just this - very short and simple - thesis seems to have triggered many very hot debates. Viewed from today's perspective, two remarks could be formulated. First: the intensity of these debates has been changing for these five decades. The first phase is in the seventies. The conservative (neoliberal) revolution initiated by $\mathrm{M}$. Thacher and $\mathrm{R}$. Reagan in 1979-1981 resulted in the marginalization of the limits-to-growth issues. Some two decades later (not incidentally in the formative years of anti/alter-globalist movements; let us invoke for instance the so-called "Battle of Seattle" in 1999) these debates revived. And second remark: it seems to us that these debates have been mainly (though not exclusively) ideological in nature: manifestations of optimism (or pessimism) as to the possibility of continuation of the strategy initiated during the Neolithic revolution (thus some 10.000 years ago) or - if interpret this strategy more specifically - during the Industrial revolution (thus some 300 years ago). And the problem is very serious and for this reason - deserves profound and comprehensive analysis. It is interesting that this type of analysis is contained in a book (published in 1973, thus soon after "Limits to Growth" which is mentioned only twice) in which the idea of "The No-Growth Society" was comprehensively and profoundly debated. Unfortunately, we have so far not come across a text continuing debates contained this book, at least in so unideological manner. (We hope that, due to our further searches, we will be able to change this opinion.)

Let us make a remark on an assumption which today seems obvious, thus - not needing any comments. However, from the philosophical point of view, assumed in our 
text, at least a brief note on this assumption should be made. We mean here the assumption that Earth will in the foreseeable future remain the only "home" of mankind. In other words speaking: other celestial bodies (the Moon, Mars etc.) will perhaps be visited - for whatever (scientific, tourist...) goals - by smaller or larger groups of people, but the visitors will be returning to the Earth. But is this assumption valid for undefined future? Surely not. But discussing the possible consequences of rejecting this assumption goes far beyond the limits of our paper.

The above remark provides us opportunity to formulate some further notes. Firstly, one of historical nature: The idea of zero growth was mentioned (probably for the first time) in 1967 in a more specific form: that of "zero population growth". And second note, of systematic character: The idea zero population growth seems to be almost obvious (the question how to estimate the upper limit of human population is another question - it has be omitted here though implies some other interesting questions) whereas the idea of zero growth of material production is (much) less obvious. If to generalize this note we could say that it might be that some parameters characterizing the global system ("spaceship Earth") can grow infinitely while the growth of some other parameters has its limits.

Let us try to elaborate on the last remark. For this purpose we will recall two theses rather widely accepted in social sciences. The first one was formulated in economics and sociology. It says that many societies have already been post-industrial societies and their economies have been service economies. And according to the second thesis (proposed and popularized by Ronald Inglehart), for economically advanced societies the shift from "material" to "non-material" values should be characteristic [29]. (In our opinion, there are some analogies and links between Inglehart's sociological theory and well known Maslow's theory of needs often presented with the image of "Maslow's pyramid"). It is by no means obvious - though is also not excluded - that the economic growth (even if defined traditionally $=$ with the GDP or GDP per capita index) is not possible without growth of material production. And even we consider the growth of material production (and it is - in market economy as opposed to command economy - measured in money rather than in tones, meters or pieces) we can think about growth (though the word "development" would be better here) resulting from the quality of products and t and not from their quantity.

To sum up our considerations on controlling (regulating) "Spaceship Earth" and its evolution: as in the case of any other process, controlling of this system/process presupposes knowledge about it and criteria of control (regulation).

One problem remains to be discussed. In abstract and general formulation - rather simple and obvious: The concept of controlling (regulating) presupposes also that of controller (regulator).In the case of many systems it is not difficult to define/indicate their controllers: sometime it is an individual, sometime a few individuals, sometime even another technical system. But in the case of the global natural-technical-social system the problem is much more difficult.

This problem is very difficult and very complex. To its possibly systematic and comprehensive discussion a separate and rather large paper (if not a book) would be necessary. But in no case the problem can be here omitted. So, we will try to make a number of brief remarks on this issue.

We start from the idea of world government. Though it has some predecessors in the ancient times and in the Middle Ages, its elaborated forms appeared in the Enlightenment epoch (e.g. I. Kant). Some versions of this idea can be found also in the $20^{\text {th }}$ century. In particular, the rise of global problems contributed to the revival if this idea. But, on the other hand, the dramatic or even tragic experiences of the previous age the experiences of authoritarian and totalitarian political systems have made most of us skeptical and cautions of the idea of world government.

Briefly put, we think that this skepticism is strongly justified. So, the idea of world government - in its literal form - should be just rejected. But of course the general intuittion: the urgent need for effectiveness and institutionalization of global governance is 
also justified (as, we hope, demonstrate it the considerations we have presented in this text). What institutions? Before we declare our views on this question, let us declare that designing such institutions and their effective construction is one of the global challenges mankind faces today. And effective designing presupposes rejection of (so natural in this domain) ideological attitudes. So good known desiderata - openness, creativeness, innovativeness... - are, in the domain of organizational/institutional, no less (rather even more) important as in the domain of technology.

Possessing neither a detailed design nor even a sketch of such design, we would like to present two general ideas which should be helpful in developing designs of global governance institutions.

First, the Locke-Montesquieu's tripartite separation of power system should be applied and developed.

Second, this system should be connected with the domain autonomy (independence) of global institutions. One could avail of some already existing mechanism. For instance, International Olympic Committee is both independent and powerful institution. Powerful - but only in the domain of sport. We could imagine that such a global institution could control (regulate) the global energy system.

Third, the personal composition of such an institution should be heterogeneous : politician and NGOs activists, corporation managers and trade unionists, "common" citizens etc.

\section{Discussion}

We have commenced this paper with some remarks on globalization. And now, approaching its end, we would like to return to this problematics. Globalization, according to the interpretation assumed here, is a complex process composed of a number of sub-processes. One of them is the rise of global problems (challenges) and the development of various human reactions (from individual emotions to international political initiatives) to those challenges. And just this process has defined the framework for our considerations presented in this text.

Taking into account the complexity and the difficult nature of the global challenges, one should not expect that a simple solution (solutions) will be found. On the contrary, the complexity of solutions should be expected to be of similar degree to that of the challenges.

There is no doubt that the development of global social consciousness (we have added here the adjective "social" to avoid any associations with parapsychology; in Internet the phrase "global consciousness" is linked with this very "science") is a n important condition for effective applying many, if not just all, solutions to global issues.

The main reason for this is rather simple: In today's world it is impossible to introduce profound (oriented at solving some global issues) changes without - at least minimal and passive - social support. And it is even better if societies (sufficiently numerous parts of them) actively demand such changes.

From a very general epistemological point of view, as open should be regarded the question whether the global social consciousness can be developed as a result of a totally spontaneous process. But we rather doubt it: the analysis of an analogous process (that of the development of national consciousness) suggests the negative answer: various activities - educational, political, propaganda etc. - seem to be necessary if the new (and in a sense "unnatural" . But even if total spontainety were to be possible, still the problem of time remains: Possibly fast development of global consciousness is desirable. To achieve this goal various activities of politicians and social-movements activists, of teachers and journalist - are necessary. As in the case of any action, the problem of effectiveness of these activities arises. 
In our opinion, also activities oriented at the developing of global consciousness should be availing of a simple yet important pedagogical (didactic) rule - applicable in virtually all domains of education (in the broadest sense of the world). According to this rule, the teacher (or anybody playing a similar role, e.g. a NGO's activist, political leader, etc.) should start from student's (reader's etc.) every-day experience and general knowledge it generates and only step-by-step broaden the perspective in which a problem is being discussed. Starting from very general and abstract ideas is most often counterproductive.

Let us try to apply this rule to the developing global consciousness. Thera are many significant and interesting works elaborating ideas which may be very important for delivering theoretical fundamentals to - let us call it so - globalist thought. For instance Hans Jonas' "The Imperative of Responsibility". In our view, it is verysignificant for the philosophy of globalization - in this its form in which it can and should be developed in academies. But if we think about such a kind of the philosophy of globalization which is addressed to a wider audience Jonas' work should be availed of cautiously and to very limited degree.

To convince "average people" to think globally and to accept (or, at least, to consider seriously and not spontaneously reject) serious changes that such thinking suggests, one should start from problems with which they are familiar and which are perceived by them as are closely conneted with the practical issues of their every-day lives.

In our opinion, the energy-related problems satisfy this condition. First of all: For the vast majority of humans, electricity plays absolutely fundamental role in the every-day life: lightening, refrigerators, washing machines, computers...elevators, metro... That production of electricity has some negative side-effects - this fact had been very poorly understood for a long time. For the last decade (since ca. 2010), the situation has been changing: floods, hurricanes and other climate determined distaters.

The activities oriented at development of global social consciousness should assume various forms. At this place, we would like to focus our attention only on this form which is today and will, at least for a long time, remain the most, so to say, "controllable" form; we mean here the school (from kindergarten to universities) education. We think that not only in our country (in Poland) but also in other countries (perhaps in all of them) profound changes in the systems of formal education are necessary. Due to obvious reasons, a systematic dyscussion of this problem is impossible here. We want to formulate here but few brief comments on it. First: All local (national) systems of education should remain differentiated but should also contain some common elements. Second: the knowledge about the structure and dynamics of global system

\section{Conclusions}

Energy (its production, supply, distribution) is one of the most important elements of the global natural-technical-social system ("Spaceship Earth"). The dynamics of energy production (supply etc.) both co-determines dynamics of the global system and is itself by this dynamics determined.

The fundamental (elementary and important) interests of all mankind (of its present and future generation) which can be shortly expressed with the word "security" - one word only - on the one hand, and the global challenges on the other - these interests and challenges generate the need for control/regulation of the global system.

Possibly comprehensive and profound knowledge of the structure and dynamics of the global system is important precondition for developing global social consciousness. However, is this knowledge is to play such a role it should be accessible not only to scientists but also to politicians, journalists, school-teachers, NGOs activist and possible large groups of citizens. Our text is an attempt at constructing a possibly simple yet comprehensive model that could be a basis for curricula. 
This model could be also a basis for constructing agendas/programs of interdisciplinary researches that should produce scientific foundations for various (national, EU...) politics (e.g. energy politics).

\begin{abstract}
Author Contributions: Conceptualization, Barbara Przybylska-Czajkowska and Waldemar Czajkowski; methodology, Barbara Przybylska-Czajkowska and Waldemar Czajkowski; resources, Barbara Przybylska-Czajkowska and Waldemar Czajkowski; writing-original draft preparation, Barbara Przybylska-Czajkowska and Waldemar Czajkowski; writing - review and editing, Barbara Przybylska-Czajkowska and Waldemar Czajkowski; funding acquisition, Barbara Przybylska-Czajkowska and Waldemar Czajkowski.
\end{abstract}

All authors have read and agreed to the published version of the manuscript

Funding: This research received funding under the research subsidy of the Faculty of Organization and Management of the Silesian University of Technology for the year 2021 (12/990/BK21/0163)

Conflicts of Interest: The authors declare no conflict of interest.

\title{
References
}

1 Rees, M. Our Cosmic Habitat, Princeton University Press: Princeton, USA, 2001

2. Scholte, A. Globalization. A Critical Introduction, 2nd ed.; Red Globe Press: London, UK, 2005

3. Mann , M. The Sources of Social Power, vol. 4: Globalizations, 1945-2011 ; Cambridge University Press: Cambridge, UK. 201

4. Mainzner, K, Thinking in Complexity. The Computational Dynamics of Matter, Mind, and Mankind; Springer Verlag: Berlin, Germany 2004

5. Gell-Mann, M. The Quark and the Jaguar. Adventures in the Simple and the Complex; W. H. Freeman \& Co: New York USA,1994

6. Beaney, M, Analysis, Stanford Encyklopedia of PhilosophySummer 2021 (07.082021)

7. Morris, W.; Brown,Ch. P. Fabvid Hume, Stanford Encyklopedia of Philosophy, Spring 2021 (07.08.2021)

8. Meadows, D.; Meadows, D.L. Limits to Growth, Potomac Associates: Falls Church, USA, 1972

9. Meadows, D.; Meadows. D.L. Beyond the limits. Global Collapse or Sustainable Future, Earthscan Publication Ltd.: London 1992

10. Randers, J 2052: a Global Forecast for the Next Forty Years, Celsea Green Publishing: Chelsea, USA, 2012

11. King, A.; Schneider, B. The First Global Revolution; Publisher: Publisher Location, Country, 1919

12. Weizsacker, E. U.; Wijkman, A. Come On! Capitalism, Short-termism, Population and the Destruction of the Planet - A Report to the Club of Rome, Springer: New York, USA, 2018

13. Fucks, R. Green Growth, Smart Growth: A New Approach to Economics, Innovation and the Environment; Anthem Press: London, UK, 2015

14. Maynard Smith, J.; Szathamary, E. The Origins of Life. From the Birth of Life to the Origin of Language, Oxford University Press: Oxford, UK, 1999

15. Jonas, H. The Imperative of Responsibility; Chicago University Press: Chicago, USA, 1984

16. Birnbacher, B. Verantwortung fur zukunftige Generationen; Reclam: Stuttgart, Germany, 1988

17. Singer, P. One World. The Ethics of Globalization, $2^{\text {nd }}$ ed. Yale University Press: New Haven, USA, 2004

18. Mann , M. The Sources of Social Power, vol. 1: A history of power from the beginning to A.D. 1750; Cambridge University Press: Cambridge, UK, 1994

19. Wright, R. The Logic of Human Destiny, Pantheon Books: New York, USA, 2000.

20. Grunwald, A., Technology Assessment: Concepts and Methods. In Philosophy of Technology and Engineering Sciences, Meijers, A., Ed.; Elsevier: Amsterdam, Netherlands , 2009; pp. 1103-1147.

21. Hancock, K.J.; Allison, J.A. The Politics of Energy in a Changing Climate: An Introduction In Hancock, K.J.; Allison, J.A. eds. The Oxford Handbook of Energy Politics; Oxford University Press: Oxford, UK, 2021, PP. 3-22

22. Boulding, K. Economy of the Coming Spaceship Earth, In H. Jarrett ed., Environmental Quality in a Growing EconomyJohn Hop kins Univerity Press, Baltimore, 1966, pp.

23. Lovelock, J. Gaja. A New Look at Life on Earth; Oxford University Press: Oxford, United Kington, 1995

24. Margulis, L Symbiotic Planet; Sciencewriters: Amherst, USA, 1988

25. Ward, P. The Medea Hypothesis, Is Life on Earth Ultimately Self-Destructive/; Princeton University Press: Princeton, USA, 2009

26. Wallerstein, I. The Modern World System, vol. 1: Capitalist Agriculture and the Origins of the European World-economy in the Sixteenth Century, Academic Press: New York, USA,1974

27. Christian, D. Big History: Between Nothing and Everything, McGraw-Hill: New York, USA, 2013

28. Grinin, L.; Korotayev, A. Great Convergence Great Divergence. A Global Perspective, Springer: New York, USA, 2015

29. Mc Neill, J. R. Something New Under the Sun.An Environmental History of the Twentieth-Century World, W.W. Norton \& Co: New 
York, USA, 2000

30. Inglehart, R. Cultural Shift in Advancef Industrial Society, Princeton University Press: Princeton, USA1990 